\title{
Chapter 16 \\ Highlights and Lessons from the \\ Implementation of an Early Warning \\ System for Glacier Lake Outburst \\ Floods in Carhuaz, Peru
}

\author{
Javier Fluixá-Sanmartín, Javier García Hernández, Christian Huggel, \\ Holger Frey, Alejo Cochachin Rapre, César Alfredo Gonzales Alfaro, \\ Luis Meza Román and Paul Andree Masías Chacón
}

\subsection{Introduction}

The Peruvian high mountains are often affected by mountain disasters such as ice and rock avalanches, Glacial Lake Outburst Floods (GLOFs), floods, or debris flows. Among them, outbursts of glacier lakes are considered as the most far-reaching glacial hazard (Kääb et al. 2005). In particular in relatively densely populated mountain ranges such as the European Alps, the Himalayas, or the tropical Andes, where

\footnotetext{
J. Fluixá-Sanmartín ( $\varangle)$ · J. García Hernández

Centre de Recherche sur l'Environnement Alpin (CREALP), Sion, Switzerland e-mail: javier.fluixa@crealp.vs.ch

J. García Hernández

e-mail: javier.garcia@crealp.vs.ch

C. Huggel · H. Frey

Department of Geography, University of Zurich (UZH), Zurich, Switzerland e-mail: christian.huggel@geo.uzh.ch

H. Frey

e-mail: holger.frey@geo.uzh.ch
}

A. Cochachin Rapre

Unidad de Glaciología y Recursos Hídricos (UGRH), Autoridad Nacional de Agua, Huaraz, Peru e-mail: jcochachin@ana.gob.pe

C. A. Gonzales Alfaro

CARE Perú, Huaraz, Peru

e-mail: cgonzales252006@gmail.com

L. M. Román

Municipalidad de Carhuaz, Carhuaz, Peru

e-mail: arq.luchomeza@gmail.com

P. A. Masías Chacón

Corporación RD S.R.L, Cusco, Peru

e-mail: paulmasias@gmail.com 
infrastructure and settlements are located within the range of potential GLOFs, the risk emanating from glacier lakes has to be addressed.

As a major element of an integrated risk management strategy, Early Warning Systems (EWSs) represent a viable and promising nonstructural tool for mitigating climate change-related risks (Bulmer and Farquhar 2010; Huggel et al. 2010). It prevents loss of life and reduces the economic and material impact of disasters. To be effective, EWS needs to actively involve the communities at risk, facilitate public education and awareness of risks, effectively disseminate messages and warnings, and ensure there is constant state of preparedness (ISDR 2006).

Four main interlinked elements of an EWS can be identified (ISDR 2006): (i) Risk Knowledge through the collection and analysis of data concerning hazards and vulnerabilities, evacuation routes, etc.; (ii) Monitoring and Warning Service, at the core of the system, for predicting and forecasting hazards, and for continuously monitoring hazard parameters, which is essential to the generation of accurate warnings in a timely fashion; (iii) Dissemination and Communication, for warnings must reach those at risk using predefined national, regional, and community appropriate communication systems; and (iv) Response Capability where education and preparedness programs play a key role.

EWSs in high-mountain contexts are highly complex systems (Frey et al. 2014; Schneider et al. 2014). On the one hand, they have to include monitoring sensors and a communication network for data and voice. On the other hand, they have to establish clear procedures, define institutional responsibilities and response measures, and most importantly involve local stakeholders to ensure that adequate actions are taken according to different warning levels.

In this paper, the main features of the EWS implemented in the Carhuaz region and the relevant lessons learned from the project are presented.

\subsection{Study Region}

The Cordillera Blanca, in the tropical Andes of Peru (Fig. 16.1), supplies water to many towns and cities located in the valley of the Callejon de Huaylas. It is however also a source of hazards due to the occurrence of ice and rock avalanches, and ensuing GLOFs which have been historically threatening the population of this area (Carey et al. 2012). More recently, in April 2010, an overflow of the glacial lake "Laguna 513" (Huaraz, Ancash) was caused by the impact of an avalanche of rock and ice, which in turn triggered a flood wave that transformed into a debris flow that impacted downstream areas reaching the city of Carhuaz. Fortunately, nobody was seriously injured, but damage to property was considerable.

This mountain range has a glacier coverage of more than $500 \mathrm{~km}^{2}$ (Racoviteanu et al. 2008), which accounts for about $25 \%$ of the world's tropical glaciers. The glacial lake "Laguna 513" (4428 $\mathrm{m}$ a.s.1., $9^{\circ} 12^{\prime} 45^{\prime \prime} \mathrm{S}, 77^{\circ} 33^{\prime} 00^{\prime \prime} \mathrm{W}$ ) formation started in the early 1970s by filling a basin that was uncovered by the shrinking Glacier 513, and several smaller lake outbursts took place in the 1980s. In the early 1990s, the 


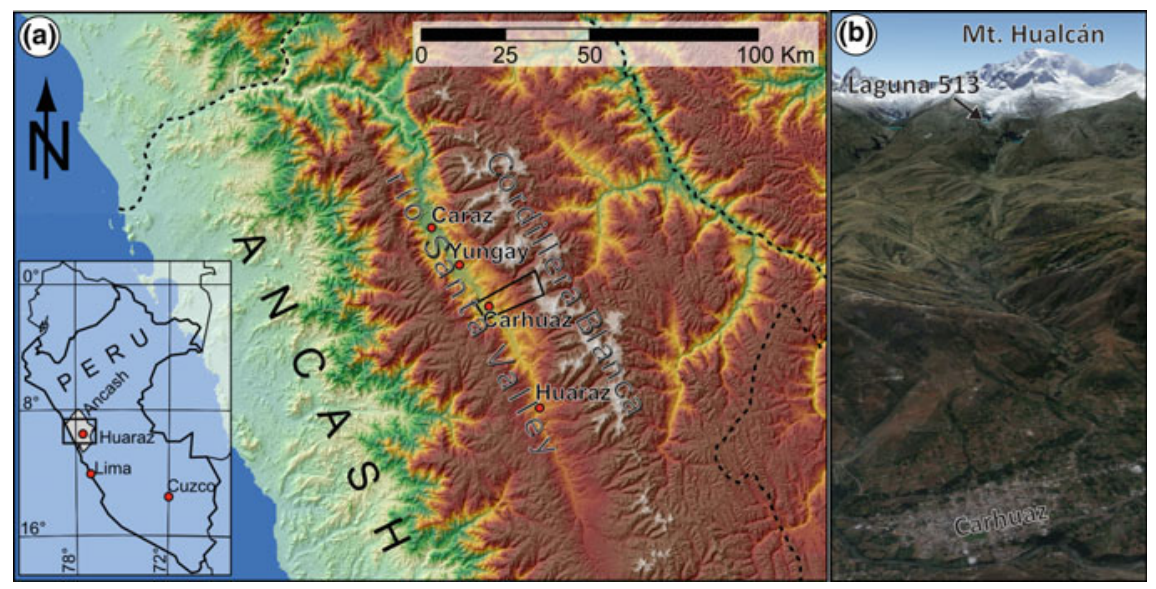

Fig. 16.1 a Location of the Cordillera Blanca, Peru (Schneider et al. 2014). Black rectangle indicates the location of b. b Oblique view of Mt. Hualcán, Laguna 513, and the city of Carhuaz in the foreground (GoogleEarth)

lake level was lowered artificially, and a permanent tunnel system was installed in the bedrock dam of the lake, a structural measure that reduces not only the probability of failure but also the social and economic consequences.

Laguna 513 is one of the 14 lakes declared as posing a high hazard in the Cordillera Blanca (ANA 2014) endangering the growing population of the Callejón de Huaylas. Due to its vicinity to the settlements, combined with the frequent avalanching and the seismic activity, an integrated hazard assessment, including a detailed study of the current hazard situation and possible future scenarios as well as measures to improve local knowledge, capacities, and specific adaptation measures, was urgently required, as emphasized in different studies (Mark and Seltzer 2005; Racoviteanu et al. 2008; Vuille et al. 2008).

From 2011 to 2015, a multidisciplinary project for sustainable reduction of climate change-related risk in high mountains was accomplished: "Glaciares 513-Adapting to climate change and reducing disaster risks due to receding Andes glaciers". Within the context of this project, an operational EWS against GLOFs was designed and implemented at Laguna 513, and the necessary emergency response protocols were developed (Muñoz et al. 2015). CARE Peru's experience implementing community EWS, and the University of Zurich with a large experience in glacier hazard and risk research, facilitated the design of this innovative and unique system in Latin America. 


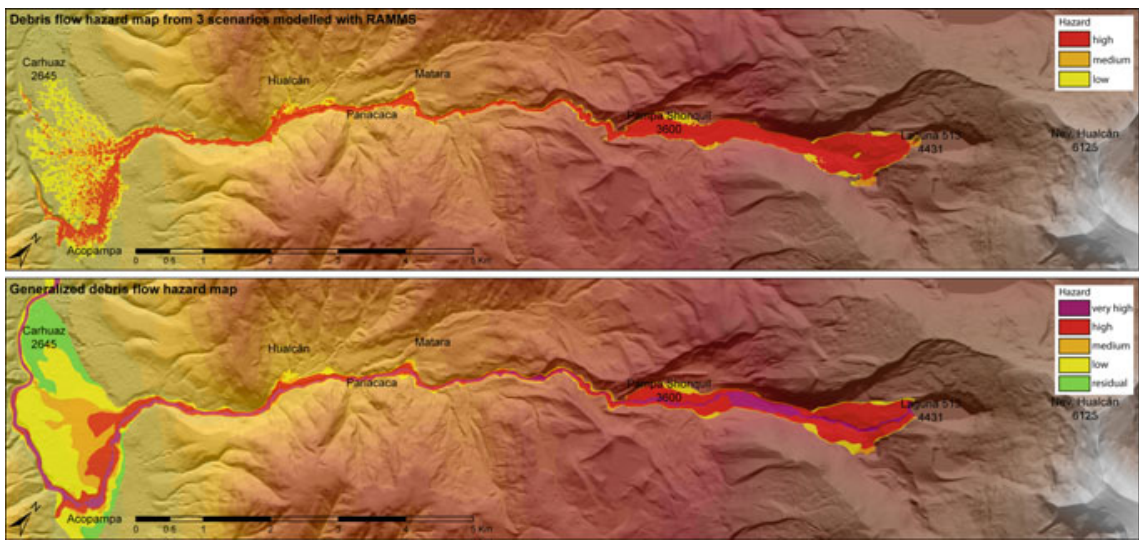

Fig. 16.2 Combined hazard levels from the three scenarios; lower panel: generalized form, corresponding to the final hazard map for GLOFs for the entire catchment (Schneider et al. 2014)

\subsection{Description of the EWS Implemented in Carhuaz}

\subsubsection{Risk Knowledge (GLOF Modeling)}

In order to assess the stability conditions of the Mount Hualcán and the response of Laguna 513 facing potential avalanches, the modeling approach used by Schneider et al. (2014) to reconstruct the 2010 outburst was used. This model chain represents the process as an iterative cascade of interacting physically based models. The model was used to simulate both the 2010 outburst and an ensemble of potential scenarios of different magnitudes, which finally resulted in a hazard map for GLOF hazards for the entire catchment, including the urban area of Carhuaz.

For the modeling, the process chain of the 2010 event was divided into three main parts: the rock-ice avalanche, the displacement wave in the lake, and the GLOF, which was further subdivided into the different flow types. For this purpose, two models were used: the hydrodynamic IBER model (IBER, 2010) for the spillover hydrograph definition and the displacement wave, and the RAMMS (RApid Mass MovementS) model (Christen et al. 2010) for the avalanche and GLOF modeling. Inundated areas modeled by RAMMS correspond well with field evidences and post-event imagery.

According to the guidelines from Raetzo et al. (2002), flow velocities and heights can be translated into different intensity levels. Three scenarios were defined: the dimensions of the 2010 event were taken for the small scenario $\left(450,000 \mathrm{~m}^{3}\right)$; the medium and large scenarios involved avalanche volumes of 1 and 3 million $\mathrm{m}^{3}$, respectively (Schneider et al. 2014). Combining those levels of intensity with the flow heights and velocities modeled for the three scenarios, the final hazard map was obtained (Fig. 16.2). This map was then used to define the evacuation routes that were assessed and approved by the civil defense platform. 


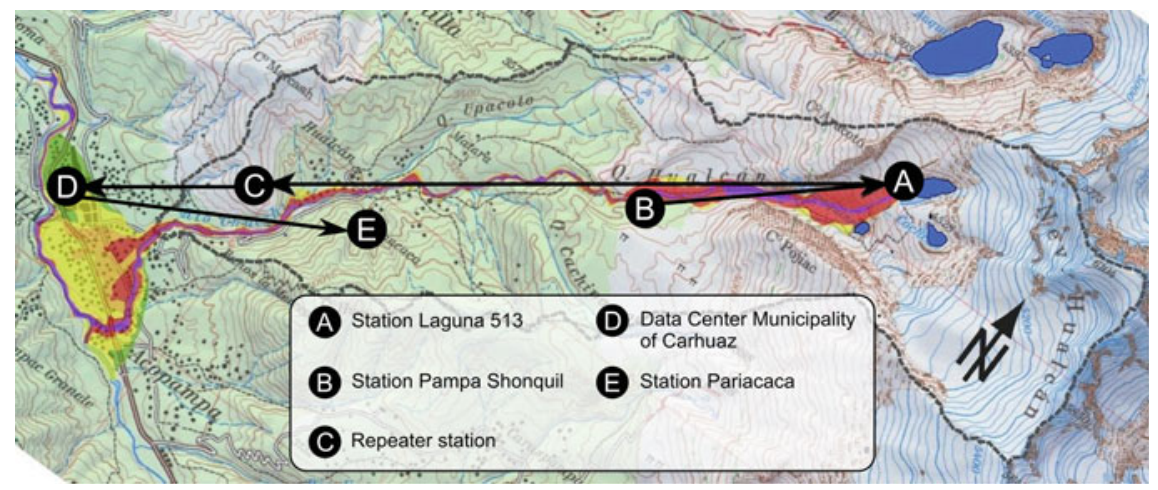

Fig. 16.3 The five stations of the EWS, arrows indicating the direction of the signal transfer. Background: topographic map from the Austrian Alpenverein and the GLOF hazard map (from Frey et al. 2014)

\subsubsection{Monitoring and Warning Service (Implementation of Stations and Sensors)}

The monitoring and warning system installed in Carhuaz comprises the following stations and sensors (Fig. 16.3):

A. Glacier and lake monitoring station at Laguna 513 (4491 m a.s.l.): four geophones (devices that record ground movements due to avalanches on Laguna 513 and convert them into voltage) mounted in the bedrock and located close to the station, measuring continuously and sending data every $5 \mathrm{~s}$; additionally, two cameras taking photos every $5 \mathrm{~s}$ during daylight hours: one oriented to the face of Mt. Hualcán, the other to the dam of Laguna 513. The station receives the signals from the geophones, the cameras and from the station at Pampa Shonquil, stores them in a data logger and broadcast them to the repeater station.

B. Hydrometeorological monitoring station at Pampa Shonquil (3600 m a.s.l.): it includes a pressure sensor installed in the Chucchún River for monitoring river water level, as well as a meteorological station with sensors for measuring air temperature and humidity, precipitation, wind speed, and solar radiation. It stores the information in a data logger and sends the signal to the station at Laguna 513 , since there is no direct view contact with the repeater station (C).

C. Repeater station (3189 $\mathbf{m}$ a.s.l.): for transferring the signal from the Laguna 513 station to the data center (D). It receives the signals from the station at Laguna 513 and broadcast them to the data center in Carhuaz.

D. Data center, located in Carhuaz in the building of the municipality (2640 m a.s.l.): it receives all information collected by the monitoring stations in real time. With this information, the mayor can take the decision to evacuate the population. It consists of a receiving antenna, a screen with real-time data access, and a server for data storage. 
E. Warning station located in the community of Pariacaca (3053 m a.s.l.): this station consists of monitoring equipment that allows the community to view real-time data of the Laguna 513. This station has two sirens that are activated from the data center (D) when a GLOF is confirmed.

All stations were equipped with solar panels and batteries for energy generation and storage, and had a mast where most of the instruments are fixed, a concreted and lockable box for the electronic equipment, and a protection fence. Energy availability is a critical and limiting factor, in particular at the station at Laguna 513, because the peaks of the Cordillera Blanca experience a much higher frequency in cloud coverage that regions further away from the main peaks. For preventing data loss and interrupted access in case of blackouts, emergency power batteries were available in the building of the municipality.

While the geophones are the principle instruments to register a potential GLOF trigger, the cameras are used as a backup as well as means for viewing the current situation, and, in particular during the test phase of the system, for relating geophone measurements to the magnitude of (avalanche) events. The pressure sensor in the riverbed at the Pampa Shonquil station adds redundancy to the system on the one hand and, if calibrations measurements are taken, can be used for continuously monitoring the runoff. Next to the station at Pampa Shonquil, there is a permanently manned hut of the wardens of the freshwater intake of Carhuaz. The warden is instructed to notify the authorities in case of an event, which is an additional and essential component of redundancy to the system.

\subsubsection{Dissemination and Communication (Data Management)}

All recorded data is stored first in the data logger at the respective station, then after data transmission ( $5 \mathrm{~s}$ intervals), on a server located in the data center and backed up on a cloud service. All the data can be assessed through a website to allow for real-time remote monitoring. In the data center itself-a dedicated office in the Municipality of Carhuaz - a screen displays the data from this web page continuously (24/7). The web page is structured in nine sub-pages: the last event for which the geophone data and several photos are shown from the moment when the geophone data exceeded the defined thresholds; the station Laguna 513 with the measurements of the geophones and small images taken by the two cameras and an indication of the charge level of the battery; the station Pampa Shonquil with the plots of the measurements of precipitation, humidity, radiation, temperature, pressure sensor, and wind speed and an indication of the charge level of the battery; the cameras showing the recent photos in higher resolution; an SMS warning module with the possibility to send out text messages manually to the registered cell phones; and the alarm activation module; a data download sub-page with the possibility to download all archived dated for a selectable time range. The sub-page of the Pampa Shonquil 
station with the meteorological measurements is publically accessible, whereas the information on the other sub-pages is only available for registered persons from the involved authorities and the project team.

While the monitoring and warning system was being designed and implemented, an action plan was elaborated in collaboration with the main stakeholders (the members of the Local Emergency Operation Center (COEL), the Civil Defense Platform, selected government members, and the mayor). The plan defines all actions to be taken according to different warning levels, as well as contact details (names and phone numbers) of responsible persons and their deputies. The definition of this action plan had to take into account local, regional, and national laws, rules, and guidelines.

If the measurements of one geophone exceed a defined threshold, an SMS is sent out to all involved persons automatically, telling to immediately check the EWS data online or in the data center. Subsequent steps have then to be taken according to the predefined action plan and based on the data available (Fig. 16.4). In this EWS, no alarm is launched automatically by the system. The thresholds of the geophones, used to activate the warning levels, are defined on the basis of a continuous data analysis which is currently being carried out jointly by different Peruvian and Swiss Institutes.

\subsubsection{Response Capability (Education and Preparedness)}

It is important that potentially affected people adequately understand the goals and procedures of the EWS and share a common interest in these efforts. It is therefore crucial to inform and train the public and the involved authorities, both technically and socially. Each actor needed a different training, according to their responsibilities and capabilities. A process of institutionalization has been carried out for local authorities (Municipality of Carhuaz, Civil Defense) in order to increase the efficiency (clear and transparent rules and simplified procedures for the implementation of risk management). It is also worth mentioning the work with the population with whom information and awareness workshops have been carried out about the real state of the danger they face. Carey et al. (2012) noted that when the population does not participate in the processes of risk management, they see the results as an imposition, causing them to resist management actions even though these will help them to save their lives.

To embody and apply learned lessons, test alarms and evacuation simulations are very effective means to train both authorities involved in the EWS and civilians (Frey et al. 2014). Such simulations can be used not only to expose the population to an evacuation under near-realistic conditions but also to test the action plan and the decision process of the responsible authorities.

Civil response to the EWS is a key aspect when assessing its effectiveness and has been tested several times since its implementation, and emergency simulations are scheduled every year for the entire country. These practices are essential for 
PROCEDURE FOR MONITORING AND EARLY WARNING IN CARHUAZ

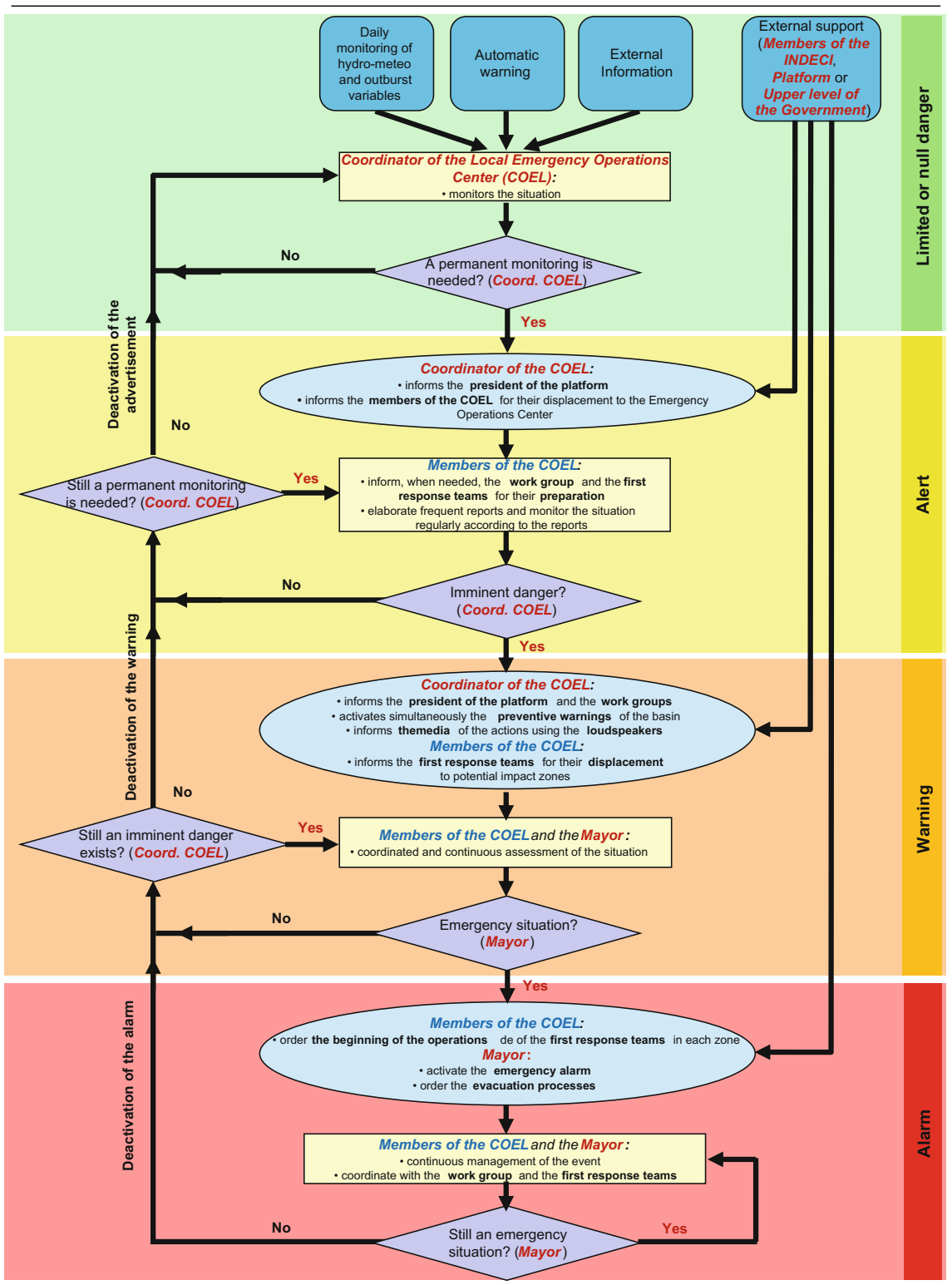

Fig. 16.4 Flowchart-type action plan for the different warning levels

improving authorities' knowledge of how well communities carry out the emergency procedures as well as to validate the feasibility of the evacuation routes derived from the hazard maps. 


\subsection{Lessons Learned and Perspectives}

This is the first EWS of its type implemented in Peru related to risks of glacier lakes, and as such, it has been a source of important lessons (technical as well as institutional) which are important for the planning of subsequent systems.

During the progress of the project, positive aspects of the implementation of the EWS, main issues encountered as well as the working areas where supplementary efforts or new approaches are needed to accomplish the objectives were identified. Moreover, as the project "Glaciares 513" reached the end of its first phase, an external and independent evaluation of the project performance identified the strengths and weaknesses regarding the implementation and exploitation of the EWS according to the following five criteria: pertinence, efficacy, efficiency, impact, and sustainability.

The main positive aspects are listed below:

1. An overall positive assessment of its implementation, even more so considering that the specialized focus on adaptation and risk management related to receding glaciers could have presented limitations. The efficacy of the project has been demonstrated as it has had the support and involvement of the population and the local authorities in activities related to glacier risk reduction (through the design and implementation of the EWS).

2. A good reception of the project and the EWS in the public and private sectors, academic and practical area, at the national, regional, and local level. The workshops carried out by the leaders of the project had a positive impact on the main stakeholders involved in the GLOF's quandary in the region. Receptivity to the implementation of an EWS of the population has been crucial because without their participation, its design would not have been possible.

3. A good response to test alarms and evacuation simulations performed during the past years. Population, local authorities, and civil defense organizations assimilated the importance of established protocols and carried out them with good results, which shows that all stakeholders appreciate the utility of such a risk management tool.

4. The installation of the technical part of the EWS (sensors, stations, etc.) was executed with the support of local staff and was accomplished without major problems. Nevertheless, it is worth mentioning the lack of experience in Peru in maintenance and operation of such systems under high-mountain conditions, which had an effect on the correct operation of the proposed EWS.

Moreover, problems encountered and improvements to be accomplished, particularly those related to technical aspects of the EWS, are the following:

1. Some communication difficulties between the project partners and the final users of the system (i.e., the Municipality of Carhuaz). This represents an opportunity to reinforce the crosswise strategies into communications, gender, monitoring accountability, and transparency in the future.

2. Key actors involvement during the project activities. Several factors-such as not all the key actors being involved since the beginning of the project, or the 
political changes in the local government of Carhuaz-resulted in a lack of comprehensive assessment of the social and political situation of the areas of intervention, and contributed to the delay in the process of implementation of certain activities and challenged the sustainability of the EWS.

3. Recurrent technical problems in the EWS causing a delay in its final operation. The proper operational functioning of the different components of the implemented EWS is highly challenging in such extreme conditions in high mountains. Several persistent technical problems (bad or null signal reception between the stations, failures due to lightning impacts, energy problems, etc.) repeatedly disturbed the operation of the system. This led to unexpected expenses, change of sensors and their disposition, and a lack of data for defining warning thresholds for the geophones signals. A proper diagnosis of the problems and an integral correction of the system scheme were then needed.

4. The alarm module of the system (sirens and their corresponding infrastructure, permanent surveillance in the municipality, etc.) was not yet implemented. This task was in the responsibility of the Municipality of Carhuaz. It is planned to install one or two long-range sirens to cover the entire area of the city of Carhuaz. In addition, the system has the possibility to send out predefined text messages to district leaders in parallel to the acoustic alarm. The populated places further up in the catchment are not included in the acoustic alarm concept at the current stage. However, they could be included in the described SMS service, given the coverage of the signal.

5. Geophones' thresholds for the activation of the different warning levels were not yet defined. At the end of the first phase of the project, the system was not yet fully operational (even if it has been tested on several occasions) because the thresholds for the geophone measurements described above that indicates when a warning level is activated were not established yet. In this test phase, three different thresholds were to be defined to make sure that smaller events got registered as well (lowermost threshold) and to have a direct indication of the size of the event, depending on only one, two, or even all three thresholds are overshot. For this, historical records of the geophones had to be taken into account, and data analysis had to be applied to them as well.

6. Further involvement of other technical fields such as electronic engineering is required. The multiple technical problems identified in the EWS, most of them caused by unexpected power source issues and deficiencies on the sensors and transmission devices, could have been solved or even avoided if an initial well-designed scheme had been elaborated which relates back to missing local experience. This could also lead to a more participative role of universities and/or research platforms on the conception and design of this (or other) EWS, benefiting both the technical aspects of the project and potential research initiatives.

7. Toward a multipurpose project. When assessing the scope of the EWS in the context of the "Glaciares 513" project, a broader perspective of adaptation to effects of climate change results in an integration of risk reduction and water resource management in the light of dwindling water resources from shrinking glaciers. Multipurpose projects have the objective to integrate both perspectives 
and thus generate multiple benefits. For the "Glaciares 513" project, a set of complementary measures were considered and evaluated with different government institutions: the construction of an additional tunnel system through the bedrock dam 30 m lower than the existing ones, with the possibility to control the discharge and further reduce GLOF risk and create reservoir capacity to release water during the dry season; a monitoring of slope stability in the surrounding of the lake with spaceborne radar interferometry (InSAR); or further climate change adaptation measures supported by local communities.

The identification of strengths and deficiencies is of importance since this pilot experience is used as a major reference for similar EWS at the national scale in Peru. A second phase of the project, called "Glaciares +. Risk Management and the Productive Use of Water from Glaciers", started in November 2015 aiming at completing and providing continuity to the incomplete processes from first phase (especially the implementation of adaptation measures to the EWS) while support to further EWS in other catchments will be provided. In order to overcome the difficulties encountered during the "Glaciares 513" project, this second phase is conceived to strengthen public management related to the issue of GLOFs, stress the legal framework as well as the planning, implementation, and monitoring of this kind of project.

The appropriate identification of technical, social, or institutional aspects to be improved is going to entitle the main leaders in the design of more robust, efficient, and resilient projects related to glacier's risk management.

\subsection{Conclusions}

In the context of the project "Glaciares 513", an early warning system was designed and implemented at Laguna 513 of the Cordillera Blanca (Ancash, Peru). The main objective was to provide the potentially affected communities with an integrated tool to reduce GLOF-related risks, most importantly to avoid any loss of live. The presented EWS is a nonstructural measure, lowering the risk by reducing the damage potential through evacuation of the population in case of an outburst. It was elaborated according to international and national standards, and consisted in the four standard components of an EWS: (i) Risk Knowledge through the modeling of GLOF events and the elaboration of hazard maps, following international standards (cf. Schneider et al. 2014); (ii) Monitoring and Warning Service, with the physical components of the system, that is the ensemble of sensors, stations, and broadcasters that detect and transmit hazard parameters to generate warnings in a timely fashion; (iii) Dissemination and Communication, through the establishment of an action plan and protocols for the management of the information generated during the detection of potentially hazardous events; (iv) Response Capability of affected population, carried out through educational programs and the performance of evacuation simulations. 
In general, the EWS had a positive impact on affected communities and a good reception by local authorities as well as social services and civil defense; the assimilation of the system by the main stakeholders was satisfying.

However, this pioneer system faces some challenges, especially when it comes to the proper functioning of electronic components (such as sensors, signal broadcasters, and batteries). The lack of continuous base data makes the definition of the geophone's warning alert thresholds yet difficult. More implication of other technical fields such as electronics is required to overcome these issues. Moreover, the involvement of key actors and the communication with them must be redefined.

By identifying these problems and weaknesses, a second phase was outlined, in which a multipurpose approach would enlarge the scope of the project and optimize the outputs. The goal of this second phase of the project ("Glaciares+, Risk Management and the Productive Use of Water from Glaciers") is to complete and provide continuity to the various unfinished processes from first phase, especially the implementation of adaptation measures to the EWS. As the main outcome of this phase, the system needs to achieve full sustainability to guarantee that the processes and activities necessary for monitoring and reducing glacier-related risks are maintained over time, generating constant and permanent results.

NOTE This article was written in May 2016; at this time, the EWS was intact and fully functional. In November 2016, a group of people accessed the monitoring station at Laguna 513 and destroyed its main components (Fraser 2017), rendering it completely useless. However, the authors consider that the lessons learned until then are still valid and of interest for the design, implementation, and improvement of such systems.

Acknowledgements The studies and works presented in this paper have been conducted under and with support of the "Proyecto Glaciares", funded by the Swiss Agency for Development and Cooperation (SDC), executed by CARE Peru, the University of Zurich, CREALP, Meteodat, Swiss Federal Institute of Technology Lausanne (EPFL), and local partners such as the Unidad de Glaciología y Recursos Hídricos, Autoridad Nacional de Agua (UGRH, ANA), and others such as the Ministerio de Ambiente, Peru (MINAM) and the National Park Service (SERNANP). We acknowledge the collaboration of several further colleagues of these institutions.

\section{References}

ANA (Autoridad Nacional del Agua), Inventario Nacional de Glaciares y Lagunas (Huaraz, 2014) Bulmer, M. H., \& Farquhar, T. (2010). Design and installation of a Prototype Geohazard Monitoring System near Machu Picchu, Peru. Natural Hazards and Earth System Sciences, 10, 2031-2038. https://doi.org/10.5194/nhess-10-2031-2010.

Carey, M., Huggel, C., Bury, J., Portocarrero, C., \& Haeberli, W. (2012). An integrated socioenvironmental framework for climate change adaptation and glacier hazard management: Lessons from Lake 513, Cordillera Blanca. Peru. Climatic Change, 112(3-4), 733-767. https://doi.org/ 10.1007/s10584-011-0249-8. 
Christen, M., Kowalski, J., \& Bartelt, P. (2010). RAMMS: Numerical simulation of dense snow avalanches in three-dimensional terrain. Cold Regions Science and Technology, 63(1-2), 1-14. https://doi.org/10.1016/j.coldregions.2010.04.005.

Fraser, B. (2017). Learning from a flood-alarm system's fate. GlacierHub. http://glacierhub.org/ 2017/05/31/learning-from-a-flood-alarm-systems-fate. Accessed October 24, 2017.

Frey, H., García-Hernández, J., Huggel, C, Schneider, D., Rohrer, M., Gonzales Alfaro, C., Muñoz Asmat, R., Price Rios, K., Meza Román, L., Cochachin Rapre, A., \& Masias Chacon, P. (2014). An early warning system for Lake Outburst floods of the Laguna 513, Cordillera Blanca, Peru. In Paper presented at the Analysis and Management of Changing Risks for Natural Hazards International conference, Padua, Italy, November 18-19, 2014.

Huggel, C., Khabarov, N., Obersteiner, M., \& Ramírez, J. M. (2010). Implementation and integrated numerical modeling of a landslide early warning system: A pilot study in Colombia. Natural Hazards, 52, 501-518. https://doi.org/10.1007/s11069-009-9393-0.

IBER. (2010). Two-dimensional modeling of free surface shallow water flow, Hydraulic reference manual, IBER v1.0.

ISDR (UN International Strategy for Disaster Risk Reduction), Developing early warning systems: a checklist. In Paper presented at the 3rd International Conference on Early Warning, Bonn, Germany, March 27-29, 2006

Kääb A., Reynolds J. M., \& Haeberli W. (2005). Glacier and Permafrost Hazards in High Mountains. In Huber U. M., Bugmann H. K. M., \& Reasoner M. A. (Eds.), Global change and mountain regions. Advances in global change research (Vol. 23, pp. 225-234). Dordrecht: Springer.

Mark, B., \& Seltzer, G. (2005). Evaluation of recent glacier recession in the Cordillera Blanca, Peru (AD 1962-1999): Spatial distribution of mass loss and climatic forcing. Quaternary Science Reviews, 24, 2265-2280. https://doi.org/10.1016/j.quascirev.2005.01.003.

Muñoz, R., Gonzáles, C., Price, K., Frey, H., Huggel, C., Cochachin, A., García, J., \& Mesa, L. (2015). Managing glacier related risks in the Chucchún Catchment, Cordillera Blanca, Peru. Abstract presented at the EGU General Assembly 2015, Geophysical Research Abstracts, Vol. 17, EGU2015-13131. Vienna, Austria, 12-17 April.

Racoviteanu, A., Arnaud, Y., Williams, M., \& Ordoñez, J. (2008). Decadal changes in glacier parameters in the Cordillera Blanca, Peru, derived from remote sensing. Journal of Glaciology, 54(186), 499-509. https://doi.org/10.3189/002214308785836922.

Raetzo, H., Lateltin, O., Bollinger, D., \& Tripet, J. (2002). Hazard assessment in Switzerland-Codes of Practice for mass movements. Bulletin of Engineering Geology and the Environment, pp. 263-268. https://doi.org/10.1007/s10064-002-0163-4.

Schneider, D., Huggel, C., Cochachin, A., Guillén, S., \& García, J. (2014). Mapping hazards from glacier lake outburst floods based on modeling of process cascades at Lake 513, Carhuaz, Peru. Advances in Geosciences, 35, 145-155. https://doi.org/10.5194/adgeo-35-145-2014.

Vuille, M., Francou, B., Wagnon, P., Juen, I., Kaser, G., Mark, B., et al. (2008). Climate change and tropical Andean glaciers: past, present and future. Earth-Science Reviews, 89, 79-96. https: //doi.org/10.1016/j.earscirev.2008.04.002. 
Open Access This chapter is licensed under the terms of the Creative Commons Attribution 4.0 International License (http://creativecommons.org/licenses/by/4.0/), which permits use, sharing, adaptation, distribution and reproduction in any medium or format, as long as you give appropriate credit to the original author(s) and the source, provide a link to the Creative Commons license and indicate if changes were made.

The images or other third party material in this chapter are included in the chapter's Creative Commons license, unless indicated otherwise in a credit line to the material. If material is not included in the chapter's Creative Commons license and your intended use is not permitted by statutory regulation or exceeds the permitted use, you will need to obtain permission directly from the copyright holder.

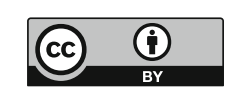

